\title{
An Interpretation of Potential Scale Dependence of the Effective
} Matrix Diffusion Coefficient

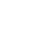

(n)

9

\author{
H.H. Liu, Y.Q. Zhang, and Q. Zhou \\ Earth Sciences Division \\ Lawrence Berkeley National Laboratory \\ Berkeley, California \\ F.J. Molz \\ Department of Environmental Engineering and Science \\ Clemson University \\ Clemson, South Carolina
}

35

36

37

38

39 


\section{Abstract.}

2 Matrix diffusion is an important process for solute transport in fractured rock, and the

3 matrix diffusion coefficient is a key parameter for describing this process. Previous

4 studies indicated that the effective matrix diffusion coefficient values, obtained from a

5 large number of field tracer tests, are enhanced in comparison with local values and may

6 increase with test scale. In this study, we have performed numerical experiments to

7 investigate potential mechanisms behind possible scale-dependent behavior. The focus

8 of the experiments is on solute transport in flow paths having geometries consistent with

9 percolation theories and characterized by local flow loops formed mainly by small-scale

10 fractures. The water velocity distribution through a flow path was determined using

11 discrete fracture network flow simulations, and solute transport was calculated using a

12 previously derived impulse-response function and a particle-tracking scheme. Values for

13 effective (or up-scaled) transport parameters were obtained by matching breakthrough

14 curves from numerical experiments with an analytical solution for solute transport along

15 a single fracture. Results indicate that a combination of local flow loops and the

16 associated matrix diffusion process, together with scaling properties in flow path

17 geometry, seems to be the dominant mechanism causing the observed scale dependence

18 of the effective matrix diffusion coefficient (at a range of scales).

20 Keywords: Matrix diffusion; Solute Transport; Scale Dependence; Fractured Rock 


\section{1. Introduction}

3 The exchange of solute mass (through molecular diffusion) between fluid in fractures

4 and fluid in the rock matrix is called matrix diffusion. Direct laboratory and field

5 evidence of matrix diffusion has been obtained in terms of an observed solute penetration

6 distance into a rock matrix (e.g., Birgersson and Neretnieks, 1990; Jardine et al., 1999;

7 Polak et al., 2003). Indirect evidence has been obtained from multi-tracer tests through

8 the significant breakthrough-curve separation of simultaneously injected tracers of

9 different matrix -diffusion coefficient values (e.g., Maloszewski et al., 1999; Karasaki et

10 al., 2000; Reimus et al., 2003a, b; Liu et al. 2004b). Owing to the orders - of magnitude

11 slower flow velocity in the matrix compared to that in fractures, matrix diffusion can

12 significantly affect solute transport in fractured rock, and therefore is an important

13 process for a variety of problems, including remediation of subsurface contamination and

14 geological disposal of nuclear waste (e.g., Neretnieks, 2002; Jardine et al., 1999).

15 The effective matrix diffusion coefficient (molecular diffusion coefficient in free

16 water, multiplied by matrix tortuosity) is an important parameter for describing matrix

17 diffusion, and in many cases largely determines overall solute transport behavior. While

18 matrix diffusion coefficient values measured from small rock samples in the laboratory

19 are generally used for modeling field-scale solute transport in fractured rock (Boving and

20 Grathwohl, 2001), several research groups recently have independently found that

21 effective matrix diffusion coefficients much larger than laboratory measurements are

22 needed to match field-scale tracer test data (Neretnieks, 2002; Becker and Shapiro, 2000;

23 Shapiro, 2001; Liu et al., 2003, 2004a). 
1 In the past, the observed enhancement of the effective matrix diffusion coefficient has

2 been attributed to different mechanisms. Shapiro (2001) suggested that large-scale

3 "effective matrix diffusion" is not a diffusive process, but actually an advective process

4 between high and low permeability zones, resulting in a significantly increased "effective

5 diffusion coefficient." Neretnieks (2002) argued that existence of fracture in-filling

6 creates relatively large areas for solute to diffuse into rock matrix, which, together with

7 the process of diffusion into stagnant water, contributes to the need for increasing the

8 effective diffusion coefficient to match the data. Wu et al. (2004) and Liu et al. (2002;

9 2003, 2004a) indicated that the existence of many small scale fractures (which

10 considerably increase the fracture-matrix interface area, but are not considered in

11 numerical models) might be the major reason for the relatively large effective diffusion

12 coefficients calculated from field data. Zhou et al. (2005a) demonstrated that the

13 existence of a degradation zone (with a relatively large matrix porosity and effective

14 matrix diffusion coefficient) near the fracture-matrix interface also contributes to the

15 observed enhancement of effective matrix diffusion coefficient. Tsang and Doughty

16 (2003) reported that the observed enhancement of the effective matrix diffusion

17 coefficient might result from the existence of so called complex fractures (Mazurek et al.,

18 2001). These complex fractures are characterized as a thin fracture zone having several

19 interconnected subfractures.

20 In addition to the observed enhancement, Liu et al. (2004b), based on a number of

21 field-test results, reported that the effective matrix diffusion coefficient might be scale

22 dependent. Zhou et al. (2005b) further reported the scale dependence by performing a

23 more comprehensive review of related field-testing results. The effective matrix diffusion 
1 coefficient, like permeability and dispersivity, seems to increases with test scale. This

2 scale dependence has important implications for large-scale solute transport in fractured

3 rock. Although a number of mechanisms have been proposed to explain the enhancement

4 of the effective matrix diffusion coefficient (mentioned above), mechanisms behind the

5 scale dependence are not fully investigated nor quantified at this stage. Liu et al. (2004b)

6 argue that transport paths in a fracture network may display fractal properties, and

7 therefore the fracture-matrix interface area (partially controlling the matrix diffusion

8 process) would be scale dependent. Consequently, observed effective matrix diffusion

9 coefficient values are also scale-dependent. Thus the major objective of this work is to

10 develop a more rigorous interpretation of the scale dependence based mainly on fracture

11 geometry.

\section{2. Methods}

13 Numerical experiments are performed in this study to investigate mechanisms behind

14 the observed scale dependence of the effective matrix diffusion coefficient. This section

15 presents methodologies used in the numerical experiments.

\subsection{A conceptual model of a water flow path in a fracture network}

17 Water flow and solute transport process in fractured rock are complicated by the

18 involved heterogeneity at different scales and the complex geometry of fracture networks.

19 Although different conceptual models for flow and transport in fractured rock exist, many

20 studies indicate that a flow pattern is mainly characterized by many flow channels (or

21 separated individual flow paths) (e.g., Tsang and Neretnieks, 1998). Different channels

22 or paths have different flow and transport properties, resulting in large-scale

23 heterogeneities. In this study, we focus on mass transfer among sub-fractures and the 
1 surrounding rock matrix associated with a single major flow path. As demonstrated later,

2 understanding this mass transfer process may hold the key to understanding why the

3 effective matrix diffusion coefficient is scale-dependent.

4 Water flow in a single flow path (or channel) has been often simplified as a flow

5 process within a single straight fracture (e.g., Neretnieks, 2002; Becker and Shapiro,

6 2003). In reality, however, flow structure is more complicated than that, owing to the

7 complexity of fracture network geometry. Percolation models (that study network

8 connectivity and characteristics of cluster structures) provide more realistic

9 representation of flow path geometry (e.g., Stauffer and Aharony, 1994; Renshaw, 1999).

10 For example, shown in Figure 1 is a twodimensional statistically isotropic bond

11 percolation network at the percolation threshold (Renshaw, 1999). A bond can be

12 considered as a single fracture within a fracture network. At percolation threshold, a

13 network forms a single connected path from the inlet (top) to the outlet (bottom), as

14 shown by heavy links in Figure 1. Obviously, the backbone (consisting of heavy links)

15 corresponds to an individual major flow path in a fracture network.

16 The backbone has several useful features. First, not all the bonds on the backbones

17 are singly connected. It is clear from Figure 1 (or other figures for bond percolation) that

18 the singly connected segments are often separated by structures which contain several

19 routes in parallel that are called loops by Stauffer and Aharony (1994). As previously

20 indicated, bonds in Figure 1 can be considered as individual fractures (Renshaw, 1999).

21 Therefore, these loops are also major features for flow pathways, as demonstrated, for

22 example, by de Dreuzy et al. (2001) and Liu et al. (2002). 
1 Second, it is well known that percolation structures at percolation threshold exhibit

2 fractal scaling properties (Stauffer and Aharony, 1994). This means that the cluster

3 structure is similar (usually statistically similar) at different scales and the size of the loop

4 will grow with the size of the network. However, when a percolation network is above

5 percolation threshold, there exist multiple globally connected clusters (or flow paths) in a

6 network. (The existence of multiple flow paths is more realistic for natural fracture

7 network.) In this case, the scaling properties are valid only for a scale smaller than the so

8 called correlation length defined as some average distance of the two bonds belonging to

9 the same cluster (Stauffer and Aharony, 1994). Roughly speaking, the correlation length

10 is proportional to the size of a typical flow loop. The scaling will not exist anymore for a

11 network with a size larger than the correlation length. In other words, the size of the loops

12 cannot grow any further with scale when it approximately reaches the half spacing of the

13 two separated flow paths.

14 Third, the above two features were originally observed for networks consisting of

15 randomly distributed bonds with the same lengths. Networks of this kind are investigated

16 in the classic percolation theories (Stauffer and Aharony, 1994). However, real world

17 fracture networks are generally more complicated, because of heterogeneity. Their

18 distribution is not purely random and may exhibit spatial correlations and individual

19 fractures are not identical. It is well documented that the trace length distribution of

20 fractures follows a power law, and longer fractures generally have larger apertures (e.g.,

21 Renshaw, 1999; de Dreuzy et al., 2001; Liu et al., 2002). In this case, the two features

22 mentioned above are still valid with additional complications (Renshaw, 1999; de Dreuzy

23 et al., 2001; Liu et al., 2002; Darcel et al., 2003). As demonstrated in de Dreuzy et al. 
1 (2001) and Liu et al. (2002), singly connected parts of a flow path consist mainly of

2 longer fractures with relatively large apertures, while the loops mainly result from

3 intersections among large fractures and relatively short fractures. Note that aperture

4 variability exists among these loops because fractures with different trace lengths are

5 involved and fracture apertures, as mentioned above, are generally correlated to the

6 fracture trace lengths.

7 It is also important to indicate that the above discussion is for bonds or fractures that

8 form backbones for a network. There are some dead-end fractures or bonds connected to

9 the backbone, as shown in Figure 1. If there is a considerable advection process between

10 fractures and the surrounding matrix, these dead-end fractures may be important for

11 enhancing fracture-matrix interaction for solute transport (Wu et al., 2004). In this

12 study, we ignore the effects of these dead-end fractures because the advection process

13 between fractures and the surrounding matrix is extremely small, as a result of the

14 negligible permeability value in the rock matrix under saturated flow conditions, i.e. the

15 water within the dead-end fractures is essentially stationary. The more important features

16 of a flow path corresponding to the backbone geometry of a fracture network (that are

17 discussed above) are used in constructing our numerical experiments.

\section{$18 \quad 2.2$ Numerical experiments}

\section{2.2.1 Construction of flow paths}

20 Numerical experiments are designed to investigate solute transport processes through a

21 flow path in a fracture network, with a focus on the effective matrix diffusion coefficient

22 as a function of distance from the source. The flow paths are constructed to be consistent

23 with the features discussed in Section 2.1. Figure 2 shows a flow path constructed using a 
1 deterministic recursive procedure. The Level 1 fracture in Figure 2 represents connected

2 long fractures that form the singly connected segments in a network and the major

3 conduit at locations where multiple loops exist. Two Level 2 fractures (with a shorter

4 trace length and smaller fracture aperture than Level 1) are then added, and an equilateral

5 triangle is formed where the loop occurs. The same procedure is continued to add Levels

$6 \quad 3$ and 4 fractures representing relatively smallscale fractures.

7 This recursive procedure enables a relatively small part of the flow path to be similar

8 to the whole flow path in shape, an important feature of a fractal. As previously indicated,

9 a flow path in a network at percolation threshold or within a scale less than the

10 correlation length is fractal, but fractal scaling behavior no longer holds for a scale larger

11 than the correlation length. Figure 3 presents a non-fractal flow path constructed by

12 removing the Level 2 fracture and those higher-level fractures connected to that fracture

13 from Figure 2. Note that the geometry of the flow path in Figure 2 exhibits a scaling

14 behavior at relatively small scales and a periodic behavior at relatively large scales.

15 We set the length and the aperture of the Level 1 fracture in Figures 2 and 3 to be $9 \mathrm{~m}$

16 and $0.001 \mathrm{~m}$, respectively. Both of these values are consistent with the fracture data in the

17 unsaturated zone of Yucca Mountain (BSC, 2004). Based on the consideration that longer

18 fractures have larger fracture apertures, and that the hydraulic conductivity of a fracture is

19 proportional to the square of the fracture aperture (e.g., de Marsily, 1986), hydraulic

20 conductivity $(\mathrm{K})$ and aperture (b) for different levels of fractures are assumed to have the

21 following relation:

$22 \frac{K_{i}}{K_{i+1}}=\left(\frac{b_{i}}{b_{i+1}}\right)^{2}=\alpha$

23 where $i=1,2$ and 3 is the level of a fracture and $\alpha>1$ is a constant. 


\section{$1 \quad$ 2.2.2 Calculation of water flow and solute transport}

2 To calculate solute transport within a flow path, we need to calculate a steady-state

3 flow rate (and velocity) for each segment in the path. Closed-form relations among a flow

4 rate, the total water flow rate, and network properties can be obtained using relations

5 derived from two basic elements (shown in Figure 3) for a flow path. Defining the

6 conductance to be the conductivity divided by the corresponding length of a given

7 segment, we can express the total conductance $\left(\mathrm{T}_{\mathrm{ab}}\right)$ from a to $\mathrm{b}$ and relations among flow

8 rates in Figure 4(a) as

$9 \quad T_{a b}=T_{1}+T_{2}$

$10 \quad Q_{1}=Q \frac{T_{1}}{T_{a b}}$

$11 Q_{2}=Q \frac{T_{2}}{T_{a b}}$

12 and for Figure 4 (b) as

$13 \quad T_{a b}=\frac{1}{\frac{1}{T_{1}}+\frac{1}{T_{2}}}$

$14 Q_{1}=Q_{2}=Q$

15 With these basic relations for flow in parallel and in serials, the flow rate in each segment

16 can be derived. Note that water flow velocity is determined as the flow rate divided by

17 the corresponding aperture. In this study, we set the total flow rate to be $0.001 \mathrm{~m}^{2} /$ day,

18 corresponding to a water flow velocity on the order of $1 \mathrm{~m} /$ day for the Level 1 fracture

19 (when flow rates at fractures of the other levels are ignored). 
1 Once the flow field is determined, we calculate solute transport within a flow path to

2 determine breakthrough curves at locations B, C, D, and E (Figures 2 and 3). The

3 calculations are based on recent theories to determine solute transport along a single flow

4 pathway with a wide range of retention processes (including matrix diffusion) and

5 spatially variable flow and transport properties (Cvetkovic et al., 2004; Painter and

6 Cvetkovic, 2005). According to these theories, the impulse-response function in the time

7 domain for such a single pathway system, which also may be viewed as the probability

8 density distribution for a unit pulse input of conservative solute, is given as (Painter and

9 Cvetkovic, 2005):

$10 \quad \gamma_{l}=\frac{H(t-\tau) B}{2 \sqrt{\pi}(t-\tau)^{3 / 2}} \exp \left[\frac{-B^{2}}{4(t-\tau)}\right]$

11 where $\mathrm{H}$ is the Heaviside function, and $\mathrm{t}$ is time. The residence time $\tau$ is defined by

$12 \tau=\int_{0}^{l} \frac{d l}{V}$

13 where $l$ is the distance between the inlet and the location where a breakthrough curve is

14 observed, and $\mathrm{V}$ is the water flow velocity along a flow pathway. The parameter $\mathrm{B}$ is

15 defined as

$16 \quad B=\int_{0}^{l} \frac{\phi \sqrt{D}}{b} \frac{d l}{V}$

17 where $\phi, \mathrm{D}$ and $\mathrm{b}$ are the matrix porosity, local matrix diffusion coefficient (molecular

18 diffusion coefficient multiplied by tortuosity factor), and local half aperture, respectively.

19 The cumulative distribution of the impulse response density (Equation (7)), which will be

20 used later, can be mathematically expressed as

$21 \quad C^{*}(t)=0 \quad$ for $t \leq \tau$ 


$$
1 \quad C^{*}(t)=\operatorname{erfc}\left[\frac{1}{2} \frac{B}{(t-\tau)^{1 / 2}}\right] \quad \text { for } t>\tau
$$

There are many different pathways between the inlet and the monitoring point for a

3 given flow path (Figures 1 and 2). Each pathway corresponds to a set of values for

4 parameters $\tau$ and B. To determine these parameter values using Equations (8) and (9), we

5 use a particle tracking scheme. We release M particles from the inlet of a flow path, and

6 track each particle from the inlet to the selected monitoring point. A particle moves with

7 a local velocity at the given segment of the network; at an intersection the probability of a

8 particle to move to a segment is determined as the ratio of flow rate for the segment to the

9 total flow rate towards the intersection. In this study, we use $\mathrm{M}=5,000$. (Our numerical

10 experiments showed that a larger $M$ value gives essentially the same results as $M=$

115,000 .) For solute transport with a constant concentration $\mathrm{C}_{0}$ at the inlet, the breakthrough

12 curve at a monitoring point is given as an average over the particles of the superposition

13 integral of the impulse-response function (Equation (10)), or

$14 \quad \frac{C(t)}{C_{0}}=\frac{1}{M} \sum_{i=1}^{M} C_{i}^{*}(t)$

15 In this study, we set the matrix porosity $\phi$ at 0.1 and the local matrix diffusion

16 coefficient $\mathrm{D}$ at $10^{-11} \mathrm{~m}^{2} / \mathrm{s}$, consistent with the corresponding data collected from the

17 unsaturated zone of Yucca Mountain, Nevada (BSC, 2005; Wu et al., 2004). Also note

18 that Equations (7)-(10) are valid only for cases in which fracture spacing is infinite, so

19 that matrix diffusion is not limited by nearby fractures. Considering that the penetration

20 depth of solute into the matrix is on the order of $\sqrt{D t_{\text {test }}}$ (where $t_{\text {test }}$ refers to the time

21 when the last observation is made in a numerical experiment), and that this depth is

22 generally much smaller than the smallest matrix block size in Figures 1 and 2 (roughly 
1 characterized by the length of a segment for a level 3 fracture), these relations are here

2 considered to be good approximations.

\section{$3 \quad$ 2.2.3 Determination of effective parameters}

4 The effective parameters (including effective matrix diffusion coefficient) may be 5 determined by fitting the numerical experiment results (Equation (11)) to the analytical

6 solution of Tang et al. (1981) for solute transport along a single fracture. A similar curve-

7 fitting approach has often been used in interpreting field-scale tracer testing results. Also

8 note that the analytical solution of Tang et al. (1981) was developed for the same

9 boundary condition (constant concentration $\mathrm{C}_{0}$ at the inlet) as that used to derive

10 Equation (11). The curve-fitting is conducted using iTOUGH2-TRAT (Zhou, 2005) by

11 minimizing an objective function defined as the summation of the square of the

12 differences (between a calculated concentration value and the corresponding

13 concentration value observed from a numerical experiment) for different observation

14 times. The iTOUGH2-TRAT program is based on iTOUGH2, a program using inverse

15 modeling for parameter estimation (Finsterle, 1999).

16 Values for the three parameters, residence time $\tau$, Peclet number $\mathrm{P}_{\mathrm{e}}=1 / \alpha_{\mathrm{L}}$ (where $\alpha_{\mathrm{L}}$

17 is dispersivity) and parameter $A=\frac{\phi \sqrt{D_{m}}}{b}$ (where $\mathrm{D}_{\mathrm{m}}$ is the effective matrix diffusion

18 coefficient) are determined from fitting an observed breakthrough curve at a given

19 monitoring location. The effective matrix diffusion coefficient is calculated from the

20 fitted value of parameter A. To make sure that the global minima of the objective

21 function to be obtained, corresponding to the best estimates of the related parameters, we

22 used the computationally intensive grid research method during the curve fitting process 
1 (Finsterle 1999). The grid search refers to the systematic evaluation of the objective

2 function in parameter space with parameter sets generated on a regular grid.

\section{3. Results and Discussion}

4 . Zhou et al. (2005b) compiled the fitted effective matrix diffusion coefficients for

5 different test sites reported in the literature and reanalyzed some tracer test results when

6 the reported diffusion coefficient values are not available from the literature. Liu et al

7 (2004b) also conducted a less comprehensive literature survey. Based on these literature

8 survey results, Liu et al. (2004b) and Zhou et al. (2005b) indicated that the effective

9 matrix diffusion coefficient for fractured rock, just like dispersivity and permeability,

10 might be scale dependent and increase with test scale. The focus of this study is to use

11 numerical experiments to further evaluate the concept of potential scale-dependence of

12 the effective matrix diffusion coefficient.

13 Based on the fact that the effective matrix diffusion coefficient is proportional to the

14 square root of the fitted parameter A (Section 2.2.3), we define the following

15 dimensionless parameter to characterize the possible scale-dependent behavior:

$16 \quad D^{*}=\left(\frac{A}{A_{\text {ref }}}\right)^{2}$

17 where $\mathrm{A}_{\text {ref }}$ corresponds to the $\mathrm{A}$ value calculated using the local matrix diffusion

18 coefficient and the aperture value for the Level 1 fracture. Obviously, D* will change

19 with travel distance from the source if the effective (fitted) matrix diffusion coefficient is

20 scale-dependent.

21 Under the methodology described previously, numerical experiments were

22 performed for solute transport in the flow path shown in Figure 2 for several $\alpha$ values 
1 including 5, 10, and 20. As indicated in Equation (1), a larger $\alpha$ gives a smaller advective

2 mass transfer from a low level fracture to relatively high-level fractures. Figure 5 shows

3 matches of breakthrough curves numerically determined at locations $\mathrm{B}, \mathrm{C}, \mathrm{D}$, and $\mathrm{E}$ in

4 Figure 2 for $\alpha=10$, using the analytical solution for solute transport in a single fracture.

5 Similar matches are obtained for other $\alpha$ values. As previously discussed, this kind of

6 match has been used in determining effective parameters, including the effective matrix

7 diffusion coefficient. The distances from the source (location A) to locations B, C, D, and

8 E to are 1, 2, 6, and $9 \mathrm{~m}$, respectively (Figure 2).

9 Shown in Figure 6 is the fitted effective matrix-diffusion coefficient as a function of

10 distance for the flow path in Figure 2 and for $\alpha=5,10$, and 20, respectively. The

11 effective matrix diffusion coefficient is indeed scale-dependent and generally increases

12 with distance. (The moderate decrease in the coefficient from $\mathrm{D}$ to $\mathrm{E}$ results from the fact

13 that the largest flow loop in the flow path exists between C and D. If the size of the flow

14 loop is much smaller than the size of flow path in flow direction, the local decrease may

15 disappear, as shown in Figure 9)) For a given distance, the effective matrix diffusion

16 coefficient generally decreases with increasing $\alpha$, because a larger $\alpha$ reduces mass

17 transfer from the Level 1 fracture to the other smaller fractures. For $\alpha=100$ (not shown

18 in Figure 6), the $\mathrm{D}^{*}$ value is reduced to one and no scale dependence is detected. In this

19 case, Level 2 and higher-level fractures essentially do not contribute to the flow and

20 transport process. As expected, the determined residence time decreases with increasing

$21 \alpha$. For example, the residence times at Location E (Figure 2) are 14, 12 and 10 days for $\alpha$

$22=5,10$, and 20, respectively. Figure 7 also shows fitted dispersivity values for numerical

23 experiments using the flow path in Figure 2. The dispersivity increases with the travel 
1 distance, which is consistent with many studies reported in the literature (e.g., Neuman,

2 1990; Gelhar, 1993). A combination of three mechanisms may contribute to the

3 scale-dependence of the effective matrix diffusion coefficient shown in Figure 6. First,

4 the scaling behavior of the flow path (i.e., the size of the flow loops and fracture matrix

5 interface area increasing with scale) in Figure 2 will generally give a larger degree of

6 fracture matrix interaction at a larger scale. This results in a larger effective matrix

7 diffusion coefficient at a larger scale. Note that the effective matrix diffusion coefficient

8 may be related to the actual fracture-matrix interface area (Liu et al., 2004a). Second,

9 the process of advective mass transport from Level 1 fractures to the other fractures

10 forming flow loops in Figure 2 is mathematically similar to the matrix diffusion and may

11 result in the scale dependence of the fitted effective matrix diffusion coefficient. (The

12 similarity of this advective transport process to matrix diffusion was used by Shapiro

13 (2001)) in interpreting certain field scale testing data.) Third, matrix diffusion within

14 these higher-level fractures may play an important role in determining the effective

15 matrix diffusion coefficient (even when the scaling in geometry of a flow path does not

16 exist). This diffusion process (which is not considered in the analytical solutions for

17 estimating the effective matrix diffusion coefficient) may result in the observed scale

18 dependence at a certain range of scales, because at a larger scale there are more solute

19 particles traveling through small-scale fractures. Note that the effective matrix diffusion

20 is inferred from parameter A (Section 2.2.3) and small fractures have large A values as a

21 result of small apertures. This third mechanism is demonstrated in Figure 8.

22 To check if the second mechanism (advective transport alone) is the dominant

23 mechanism for the observed scale dependence, we conducted a numerical experiment 
1 using the flow path in Figure 2 and for $\alpha=5$. Specifically, we reduced the local matrix

2 diffusion coefficient by 100 times. If the advective process were indeed the dominant

3 mechanism, the effective matrix diffusion coefficient determined from the numerical

4 experiments would not change significantly with the change in the local matrix diffusion

5 coefficient. The determined effective matrix diffusion coefficients are also shown in

6 Figure 6. Obviously, values for these coefficients are significantly smaller than those with

7 the higher local matrix diffusion coefficient (Figure 6). Therefore, matrix diffusion within

8 fractures including small scale fractures, rather than the advective transport between

9 fractures at different levels alone, is the ultimate process for determining the effective

10 matrix diffusion coefficient and its scale dependence. However, advective transport to

11 (high-level) small fractures is needed to move solute to these fractures from Level 1

12 fracture for the matrix diffusion processes. Without this advection, matrix diffusion in

13 these small fractures would not be able to occur.

14 As previously indicated in Section 2.1, the scaling of the network geometry for a flow

15 path does not always exist especially when the size of a network is larger than the

16 correlation length. To investigate the solute transport process in a network without

17 scaling properties in geometry, we performed a numerical experiment using the flow path

18 in Figure 3 for $\alpha=5$. The flow path does not have scaling properties in geometry at large

19 scales. (As shown in Figure 3, the scale under which the scaling in flow-path geometry

20 holds is $3 \mathrm{~m}$ for this particular flow path.) Numerical experiment results observed at

21 locations B, C, D and E (Figure 3) are matched to determine values for the effective

22 parameters (Section 2.2.3). As shown in Figure 9, the effective matrix diffusion

23 coefficient is still scale-dependent for the given distance range from A to E. This seems 
1 to demonstrate that the existence of local flow loops and the associated matrix diffusion

2 process can result in scale dependence for travel distances beyond the scale under which

3 the scaling properties in geometry exists.

4 However, this study cannot exclude that a constant $\mathrm{D}^{*}$ can be reached for travel

5 distances much larger than that from A to E (Figure 3), owing to the lack of scaling

6 properties in the flow path geometry at relatively large scales. The existence of the

7 constant $\mathrm{D}^{*}$ at relatively large scales may be similar to the asymptotic behavior of

8 macroscopic dispersivity for a flow field characterized by a stationary random

9 permeability distribution (Gelhar, 1993). While the focus of this study is on possible

10 mechanisms behind the observed scale dependence of the effective matrix diffusion

11 coefficient, we will leave the potential asymptotic behavior of $\mathrm{D}^{*}$ at much larger scales to

12 future research.

13 Theabove discussions indicate that a combination of local flow loops, matrix diffusion

14 process associated with these loops, and scaling properties in flow-path geometry, seems

15 to be a major mechanism causing the scale dependence of the effective matrix diffusion

16 coefficient observed at a range of scales. The scaling properties in flow-path geometry

17 causes the increase in $\mathrm{D}^{*}$ at scales within which scaling holds. The matrix diffusion

18 processes associated with flow loops results in further increases in $\mathrm{D}^{*}$ at relatively large

19 scales. The advective process within flow loops is responsible for feeding solute into

20 matrix diffusion processes within the related sub-fractures.

21 Tables 1-3 give values for the fitted (effective) transport parameters for different

22 numerical experiments. Because both dispersion and matrix diffusion processes can cause

23 the spreading in the observed breakthrough curves, one may be concerned with the 
1 possibility that the scale dependence of the effective matrix diffusion coefficient is an

2 artificial effect of the scale dependence of the dispersivity. This is not the case here. For

3 example, Sánchez-Vila and Carrera (2004) theoretically demonstrated that the artificial

4 matrix diffusion coefficient (when dispersion is completely ignored in the model)

5 resulting from the actual dispersion process is inversely proportional to the dispersivity.

6 Because the dispersivity increases with travel distance, one would not observe an

7 increase in matrix diffusion coefficient with scale if the dispersion were artificially

8 considered a major component of matrix diffusion process. The above argument is also

9 supported by our simulation results showing a strong dependence of the effective matrix

10 diffusion coefficient on the local diffusion coefficient.

12 The importance of flow-path geometry for the effective matrix diffusion coefficient

13 values determined from the field tests based on simplified flow geometry is supported by

14 the recent study by Neretnieks and Moreno (2003). They reported that matrix diffusion

15 coefficient values much larger than the lab data were needed to match the results of tracer

16 tests conducted at Äspö Hard Rock Laboratory in previous studies. Based on high-

17 resolution transmissivity measurements in five boreholes at the test site, they concluded

18 that there were many more conductive fractures than those assumed in previous studies.

19 By including these new small-scale fractures with relatively small permeability values,

20 they were able to reasonably reproduce the tracer test results with matrix diffusion

21 coefficient values measured from the rock matrix samples. Conceptually, this is similar to

22 a fact that if heterogeneity is adequately resolved for a natural porous medium in a

23 numerical model, the value for the effective (large scale) dispersivity can be reduced to a 
1 local-scale value. However, it is practically difficult, if not impossible, to characterize

2 fractures at different scales (or heterogeneity at different scales for porous media) for

3 large-scale problems. Nevertheless, Neretnieks and Moreno (2003) demonstrated that

4 small-scale fractures are indeed an important factor contributing to the differences

5 between lab-scale and field-scale effective matrix diffusion coefficient values, which is

6 consistent with our study results here.

7 Figure 10 shows a comparison between our simulated results for the two flow paths and a

8 portion of data points reported by Zhou et al. (2005b) who surveyed effective matrix

9 diffusion coefficient values from different test sites with test scales up to more than 1000

$10 \mathrm{~m}$. The parameter Fd refers to the ratio of the effective matrix diffusion coefficient value

11 to its local scale value, and is equivalent to D* (Equation (12)) for this specific study. The

12 data points correspond to those from non-Granite fractured rock (with test scales less than

$13100 \mathrm{~m}$ ) because our simulations are roughly based on parameter values from the

14 unsaturated zone of Yucca Mountain that is not Granite. For a given travel distance (test

15 scale) in the figure, the simulation result refers to the average $\mathrm{D}^{*}$ values for the two flow

16 paths shown in Figures 6 and 9. (The case with the reduced local diffusion coefficient is

17 not included.) Figure 10 also shows two data points corresponding to the geometric

18 means of data at both the rock matrix sample scale and a tens of meters scale. A test scale

19 of $5 \mathrm{~cm}$ is assumed for a rock matrix sample. Note that by definition, $\mathrm{Fd}$ is always equal

20 to one at the rock matrix sample scale, and that data point actually represents many

21 overlapped data points because each field-scale data point corresponds to one data point

22 at the rock sample scale. (The data set reported in Zhou et al. (2005) indicates that the

23 geometric means for the effective matrix diffusion coefficient are about 10 and 100 , 
1 respectively, for test scales of tens of meters and hundreds of meters.) We need to keep in

2 mind that the comparison here is largely qualitative. This is because details of small-scale

3 fractures for the test sites are not available and the assumed high level (small scale)

4 fractures in our simulations are not necessarily representative for a particular test site.

5 Nevertheless, our simulation results are within the range of the test data. While there is a

6 large degree of fluctuation in $F_{d}$ data points, the geometric mean of these values for test

7 scales between several meters to $100 \mathrm{~m}$ is about 10 , as mentioned above. Our simulation

8 result $\left(\mathrm{F}_{\mathrm{d}}\right.$ value $)$ at a scale of about $10 \mathrm{~m}$ is 4.3 , which is not too far from the geometric

9 mean. Also note that our simulation results are generally on the lower side of the test data

10 (Figure 10). This may imply that in addition to the effects of flow geometry, other

11 mechanisms also contribute to the scale dependence. As a matter of fact, most recently

12 Liu et al. (2006) theoretically investigated effects of rock matrix heterogeneity on the

13 scale dependence of the effective matrix diffusion coefficient, and found that the

14 heterogeneity indeed potentially contributes to the scale dependence. It is very likely that

15 the scale dependence of the effective matrix diffusion coefficient is a result of a

16 combination of different mechanisms and the flow geometry is one of them. More studies

17 are needed to fully understand this important scale-dependent behavior.

\section{4. Concluding Remarks}

19 It has been recognized that matrix diffusion is an important process for retarding

20 solute transport in fractured rock, and the matrix diffusion coefficient is a key parameter

21 for describing this process. Previous studies indicated that the effective matrix -diffusion

22 coefficient values, obtained from a number of field tracer tests, are enhanced in

23 comparison with the local values and may increase with test scale. In this study, we have 
1 performed numerical experiments to investigate the potential mechanisms behind this

2 scale dependence. The focus of our numerical experiments is on transport in flow paths

3 having geometries consistent with percolation theories. The current results indicate that a

4 combination of the local flow loops and the associated matrix diffusion process, together

5 with scaling properties in flow path geometry, seems to be the major mechanism (at a

6 range of scales) for the observed scale dependence of the effective matrix diffusion

7 coefficient, while other potentially important mechanisms may still exist and need to be

8 investigated in future studies.

9

10

11 


\section{Acknowledgment}

2 We are indebted to Guoxiang Zhang and Daniel Hawkes at Lawrence Berkeley National

3 Laboratory (LBNL) for their careful review of a preliminary version of this manuscript. This

4 report was prepared by LBNL pursuant to a contract funded by the United States Department of

5 Energy (DOE), Office of Civilian Radioactive Waste Management (OCRWM), Office of Science

6 and Technology and International (OST\&I) and neither, LBNL nor any of its contractors or

7 subcontractors nor the DOE/OCRWM/OST\&I, nor any person acting on behalf of either: makes

8 any warranty or representation, express or implied, with respect to the accuracy, completeness, or

9 usefulness of the information contained in this report, or that the use of any information,

10 apparatus, method, or process disclosed in this report may not infringe privately-owned rights; or

11 assumes any liabilities with respect to the use of, or for damages resulting from the use of, any

12 information, apparatus, method, or process disclosed in this report. Reference herein to any

13 specific commercial product, process, or service by trade name, trademark, manufacturer, or

14 otherwise, does not necessarily constitute or imply its endorsement, recommendation, or favoring

15 by DOE/OCRWM/OST\&I. The views, opinions, findings, and conclusions or recommendations

16 of authors expressed herein do not necessarily state or reflect those of the

17 DOE/OCRWM/OST\&I. 


\section{References}

2 Becker, M. W., Shapiro, A. M., 2000. Tracer transport in fractured crystalline rock:

3 Evidence of non-diffusive breakthrough tailing. Water Resour. Res., 36(7), 1677$4 \quad 1686$.

5 Birgersson, L., Neretnieks, I., 1990. Diffusion in the matrix of granitic rock: field test in 6 the Stripa mine. Water Resour. Res., 26(11), 2833-2842.

7 Boving, T. B., Grathwohl, P., 2001. Tracer diffusion coefficients in sedimentary rocks:

8 Correlation to porosity and hydraulic conductivity. J. Contam. Hydrol., 53, 85-100.

9 BSC, 2004. Analyses of Hydrologic Properties Data. ANL-NBS-HS-000042 (Rev 00).

10 Cvetkovic, V., Painter, S., Outters, N., Selroos, J.-O., 2003. Stochstic simulation of

11 radionuclide migration in discretely fractured rock near Äspö Hard Rock Laboratory.

12 Water Resour. Res., 40, W02404, doi:10.1029/2003WR002655.

13 Darcel C., Bour, O., Davy, P., de Dreuzy, J.R., 2003. Connectivity properties of two14 dimensional fracture networks with stochastic fractal correction. Water Resour. Res., 15 39(10), 1272, doi:10.1029/2002WR001628.

16 de Dreuzy J. R., Davy, P., Bour, O., 2001. Hydraulic properties of two-dimensional

17 random fracture networks following a power law length distribution: 1. Effective 18 connectivity. Water Resour. Res., 37(8), 2065-2078.

19 de Marsily, G., 1986. Quantitative Hydrogeology. Academic, San Diego, Calif..

20 Finsterle, S., 1999. ITOUGH2 user's guide. Report LBNL-40040, UC-400, Lawrence 21 Berkeley National Laboratory, Berkeley, CA.

22 Gelhar, L. W., 1993. Stochastic Subsurface Hydrology. Prentice Hall, New York. 
1 Jardine, P. M., Sanford, W. E., Gwo, J.P., Reedy, O.C., Hicks, D. S., Riggs, J. S., Bailey,

2 W. B., 1999. Quantifying diffusive mass transfer in fractured shale bedrock. Water

3 Resour. Res., 35(7), 2015-2030.

4 Karasaki, K., Freifeld, B., Cohen, A., Grossenbacher, K., Cook, P., Vasco, D., 2000. A

5 multidisciplinary fractured rock characterization study at Raymond field site,

6 Raymond. CA, J. Hydrol., 236(1-2), 17-34.

7 Liu, H. H., Haukwa, C.B., Ahlers, C.F., Bodvarsson, G.S., Flint, A.L., Guertal, W.B.,

8 2003. Modeling flow and transport in unsaturated fractured rock: an evaluation of the

9 continuum approach. J. Contam. Hydrol., 62-63, 173-188.

10 Liu, H. H., Salve, R., Wang, J.S., Bodvarsson, G.S., Hudson, D., 2004a, Field

11 investigation into unsaturated flow and transport in a fault: model analyses. J. Contam.

12 Hydrol., 74(1-4), 39-59.

13 Liu, H. H., Bodvarsson, G.S., Zhang, G., 2004b. Scale dependency of the effective matrix 14 diffusion coefficient. Vadose Zone J., 3, 312-315.

15 Liu, H.H., Bodvarsson, G.S., Finsterle, S., 2002. A note on unsaturated flow in two16 dimensional fracture network. Water Resour. Res., 38(9), 1176, 17 doi:10.1029/2001WR000977.

18 Liu, H. H., Zhang, Y. Q., Molz F. J., 2006. Scale dependency of the effective matrix 19 diffusion coefficient: Some analytical Results. Vadose Zone J. (in review).

20 Maloszewski, P., Herrmann, A., Zuber, A., 1999. Interpretation of tracer tests performed 21 in a fractured rock of the Lange Bramke Basin, Germany. Hydrogeol. J., 7, 209-218. 
1 Mazurek, M., Bossart, P., Hermanson, J., 2001. Classification and characterization of

2 water conducting features at Äspö. in Proceedings of International Semina First TRUE

3 stage, Rep. TR-01-24, pp.203-208, Swed. Nucl. Fuel and Waste Manag. Co. (SKB),

4 Stocholm.

5 Neretnieks, I., 2002. A stochastic multi-channel model for solute transport-analysis of

6 tracer tests in fractured rock. J. Contam. Hydrol., 55, 175-211.

7 Neretnieks, I. Moreno L., 2003. Prediction of some in situ tracer tests with sorbing tracers

8 using independent data. J. Contam. Hydrol., 61, 351-360.

9 Neuman, S. P., 1990. Universal scaling of hydraulic conductivities and dispersivities in 10 geologic media. Water Resour. Res. 26 (8):1749-1758.

11 Painter, S., Cvetkovic, V., 2005. Upscaling discrete fracture network simulations: An

12 alternative to continuum transport models. Water Resour. Res., 41, W02002, 13 doi:10.1029/2004WR003682.

14 Polak, A., Grader, A.S., Wallach, R., Nativ, R., 2003. Chemical diffusion between a 15 fracture and the surrounding matrix: Measurement by computed tomography and 16 modeling. Water Resour. Res., 39(4), 1106, doi:10.1029/2001WR000813.

17 Reimus, P. W., Haga, M.J., Adams, A.I., Callahan, T.J., Turin, H.J., Counce, D.A., 18 2003a. Testing and parameterizing a conceptual solute transport model in saturated 19 fractured tuff using sorbing and nonsorbing tracers in cross-hole tracer tests. J. 20 Contam. Hydrol., 62-63, 613-636.

21 Reimus, P., Pohll, G., Mihevc, T., Chapman, J., Haga, M., Lyles, B., Kosinski, S., 22 Niswonger, R., Sanders, P., 2003b. Testing and parameterizing a conceptual model for 
1 solute transport in a fractured granite using multiple tracers in a forced-gradient test.

2 Water Resour. Res., 39(12), 1356, doi:10.1029/2002WR001597.

3 Renshaw C. E., 1999. Connectivity of Joint networks with power law length 4 distributions. Water Resour. Res., 35(9), 2661-2670.

5 Sánchez-Vila, X. Carrera J., 2004. On the striking similarity between the moments of

6 breakthrough curves for heterogeneous medium and a homogeneous medium with a

7 matrix diffusion term. J. Hydrol., 294, 164-175.

8 Shapiro, A. M., 2001. Effective matrix diffusion in kilometer-scale transport in fractured $9 \quad$ crystalline rock. Water Resour. Res., 37(3), 507-522.

10 Staffer D., Aharony, A., 1994. Introduction to Percolation Theory. Taylor \& Francis, 11 Bristol, PA..

12 Tang, D. H., Frind, E.O., Sudicky, E.A., 1981. Contaminant transport in a fractured 13 porous media: Analytical solution for a single fracture. Water Resour. Res., 17(3), $14555-564$.

15 Tsang C. F., Doughty, C., 2003. A particle-tracking approach to simulating transport in a 16 complex fracture. Water Resour. Res., 39(7), 1174, doi:10.1029/2002WR001614.

17 Tsang C.F., Neretnieks, I., 1998. Flow Channeling in Heterogeneous Fractured Rocks.

18 Reviews of Geophysics, Vol. 36, No. 2, 275-298.

19 Wu, Y. S., Liu, H.H., Bodvarsson, G.S., 2004. A triple-continuum approach for modeling 20 flow and transport processes in fractured rock. J. Contam. Hydrol. 73, 145-179. 
1 Zhou Q., Liu, H.H., Molz, F.J., Bodvarsson, G.S., 2005a. Evidence of Multi-Process

2 Matrix Diffusion in a Single Fracture from a Field Tracer Test. Transport in Porous 3 Media (in press).

4 Zhou Q., Liu, H.H., Molz, F.J., Zhang, Y., Bodvarsson, G.S., 2005b. Effective matrix 5 diffusion coefficient for fractured rock: Results from a literature survey (in review).

6 Zhou, Q., 2005. iTOUGH2-TRAT Qualification Report. Lawrence Berkeley National 7 Laboratory, Berkeley.

8

9

10

11

12

13

14

15

16

17

18

19

20 
1 Figure 1. A two-dimensional bond percolation network at the percolation threshold (after 2 Renshaw (1999)). The heavy links correspond to the backbone.

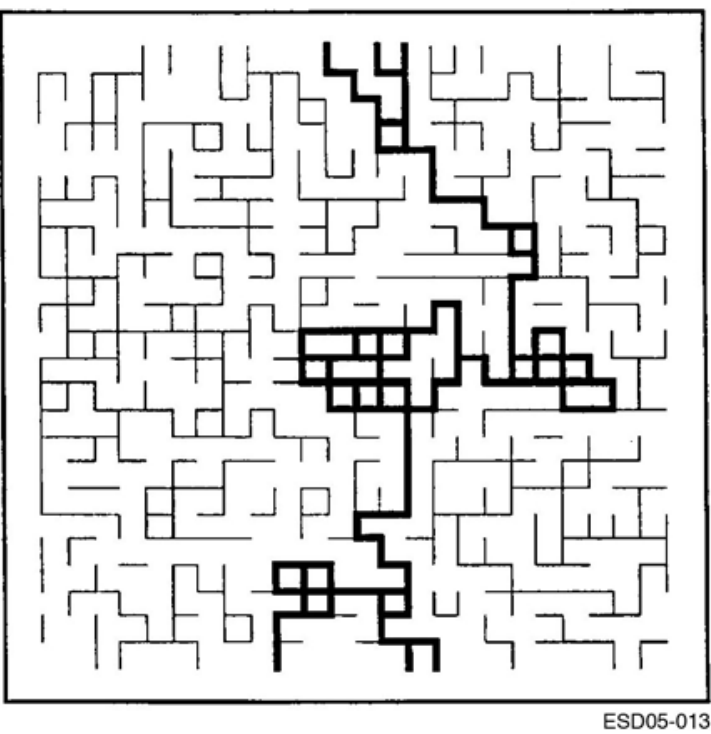


1
2
3

Figure 2. A flow path characterized by scaling behavior.

4
5
6
7
8
9
10
11
12
13
14
15
16
17
18
19
20
21
22
23
24
25

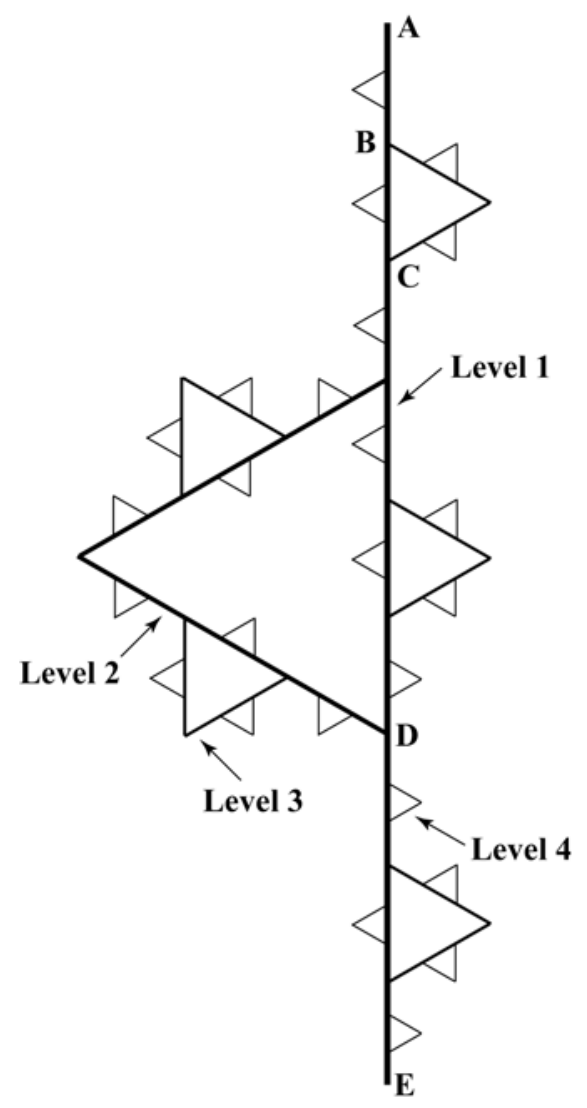

30 
1 Figure 3. A flow path generated by removing Level 2 fracture and the associated higher2 level fractures from the path in Figure 2.

3

4
5
6
7
8
9
10
11
12
13
14
15
16
17

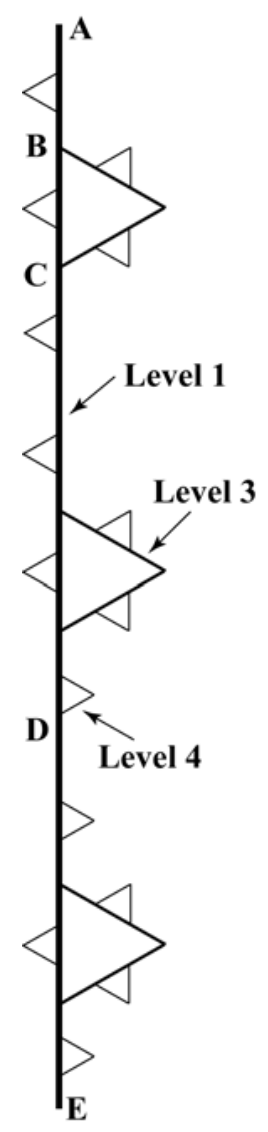

18

19

20

21

22

23

24

31 
2

3 4

Figure 4 Basic elements of a flow path that are used to calculate and distribute flow rates.

(a)

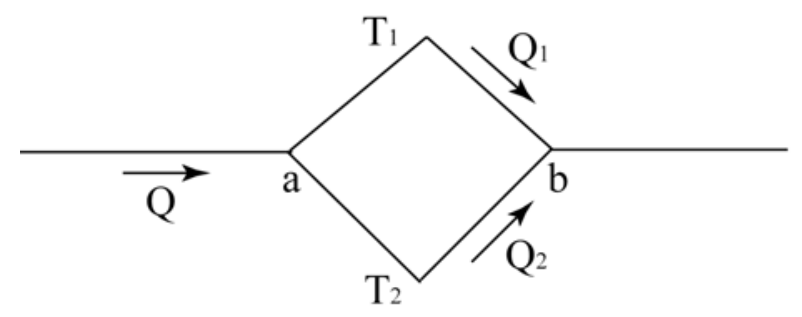

(b)

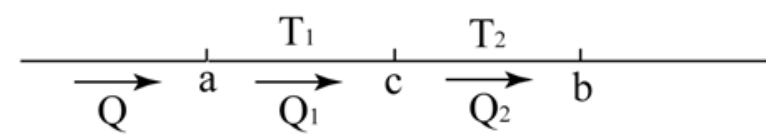


1 Figure 5. Matches of numerical experiment results (dashed lines) with the analytical 2 solution to solute transport through a single fracture (solid lines) at locations B, C, D and 3 E for the flow path shown in Figure 2.
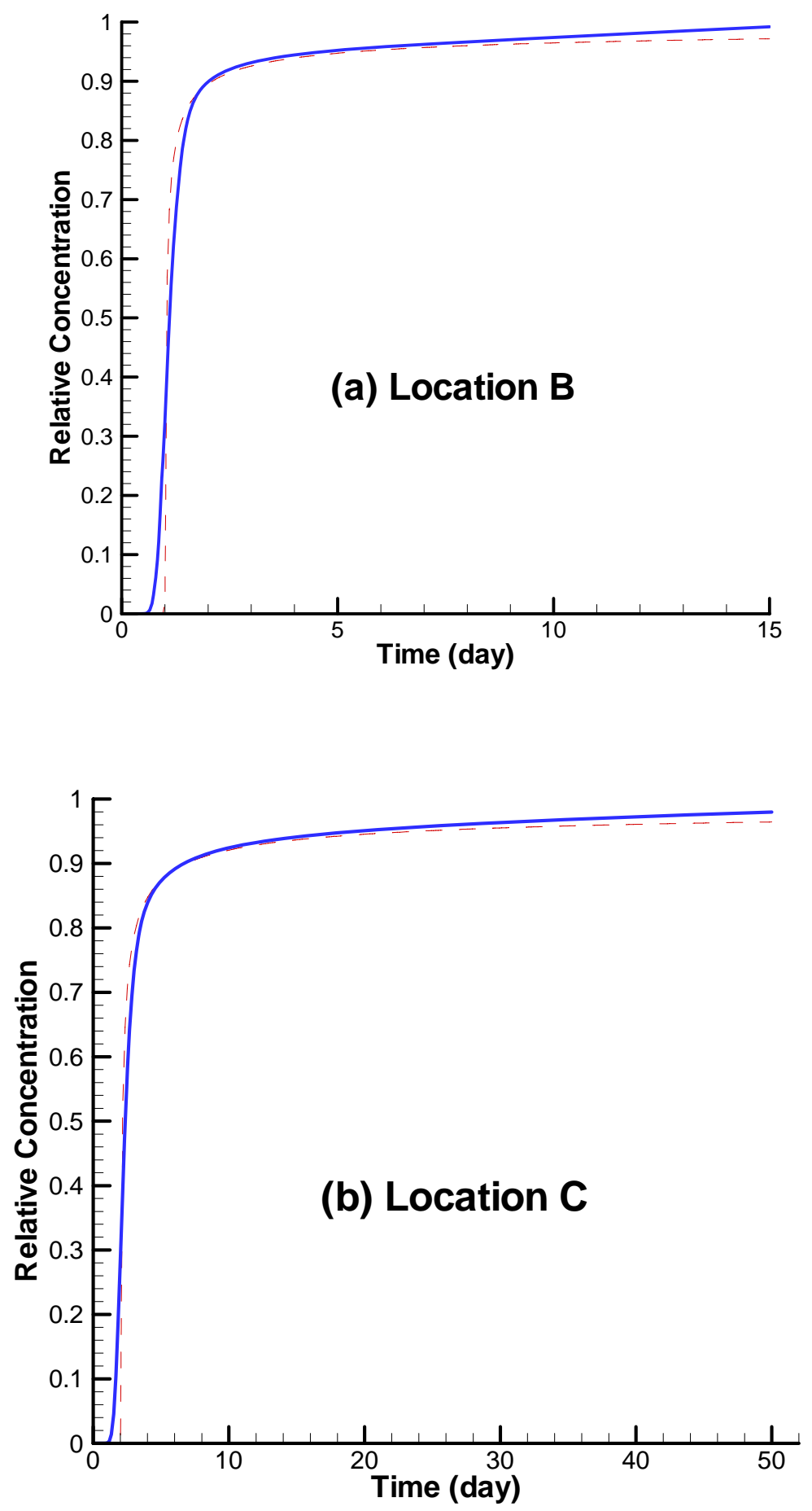


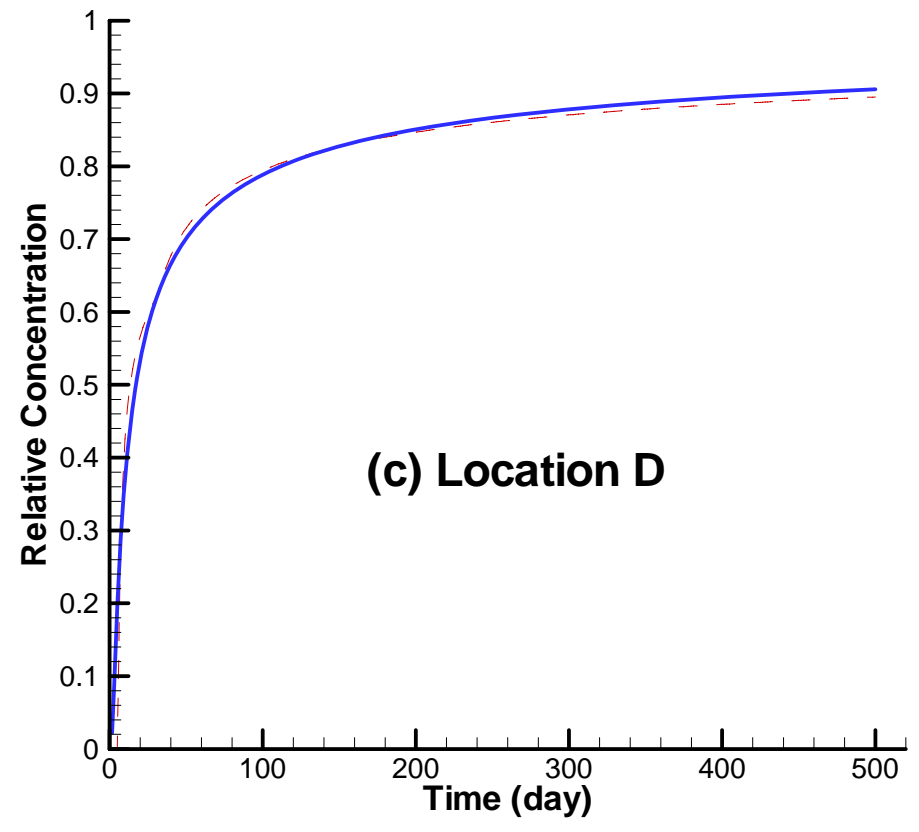

2

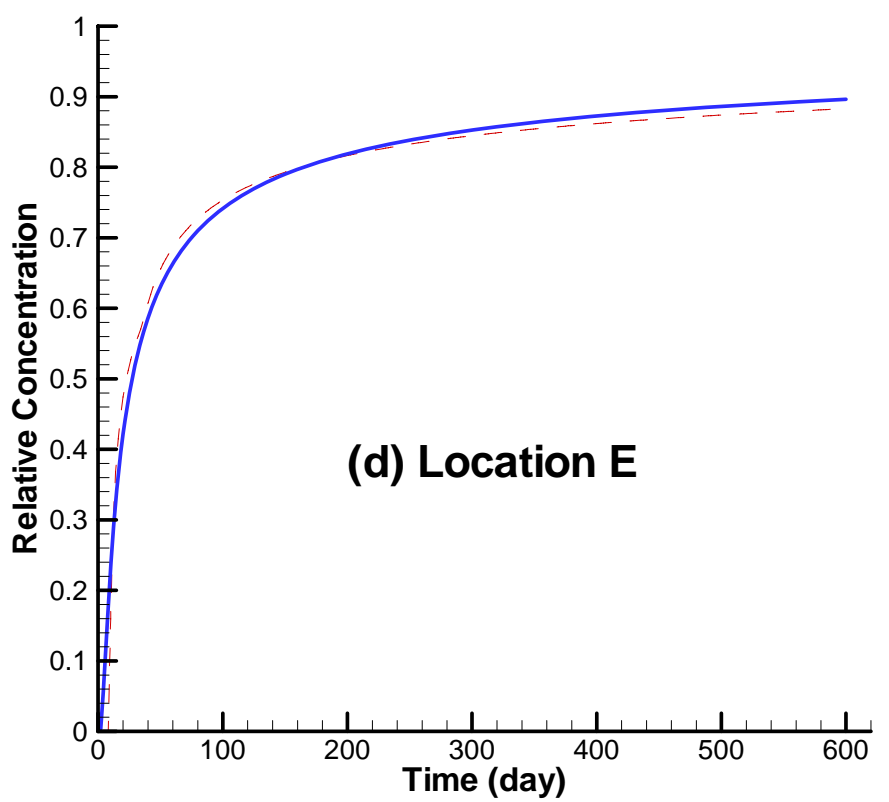

3
4
5
6
7
8
9
10 
1 Figure 6. Fitted relative effective-matrix-diffusion coefficient values (Equation (12)) as a 2 function of distance for the flow path shown in Figure 2. The curve labeled with "reduced 3 D" corresponds to the local matrix diffusion coefficient reduced by 100 times (as 4 compared with the other curves).

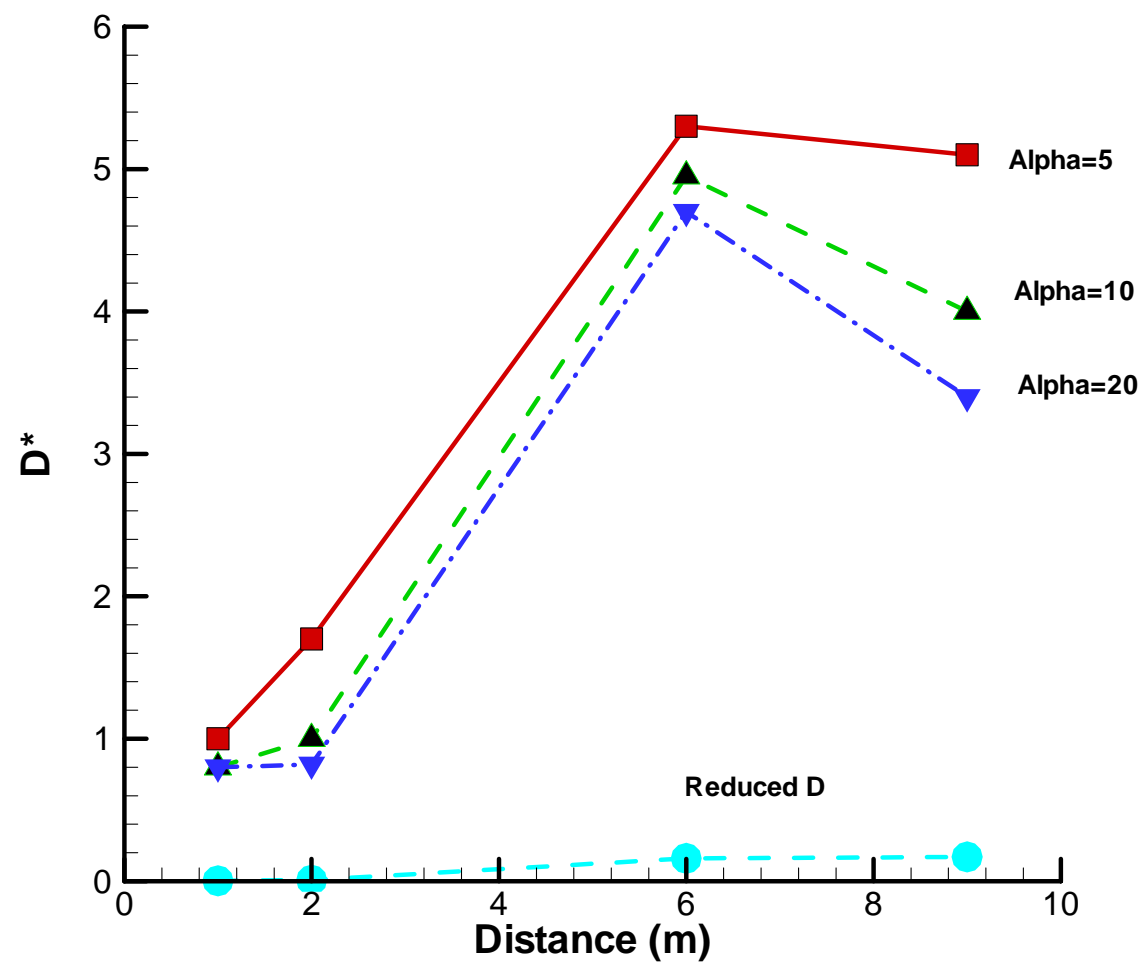


2

3

4 Figure 7. Fitted dispersivity values as a function of distance for the flow path shown in 5 Figure 2.

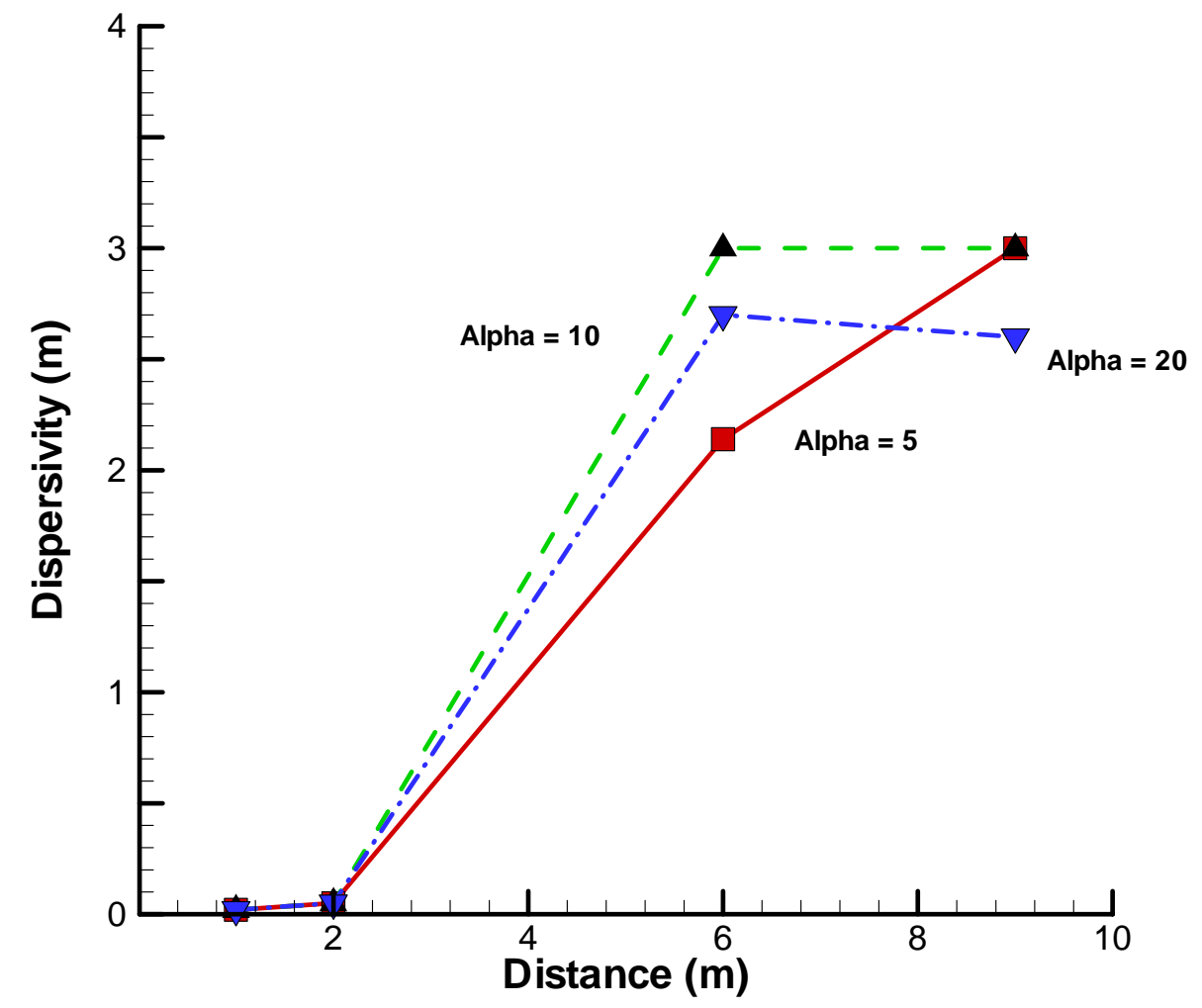


10

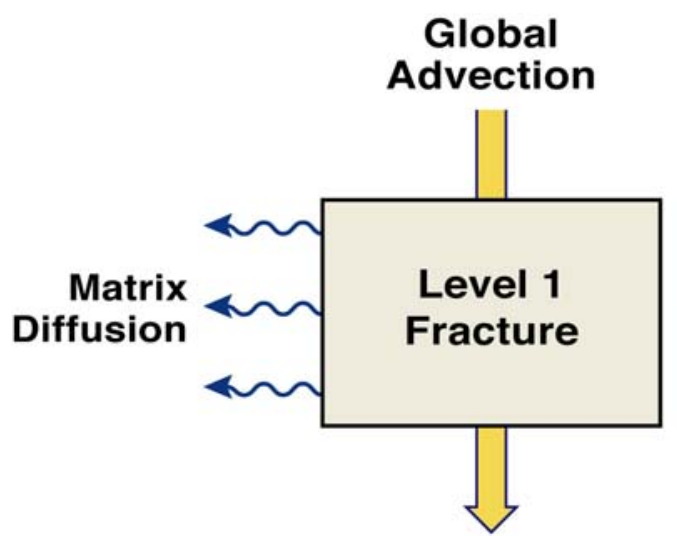
diffusion in fractures at different scales.
Figure 8. Effective matrix diffusion as a combination of local-scale advection and matrix

\section{Local} Advection

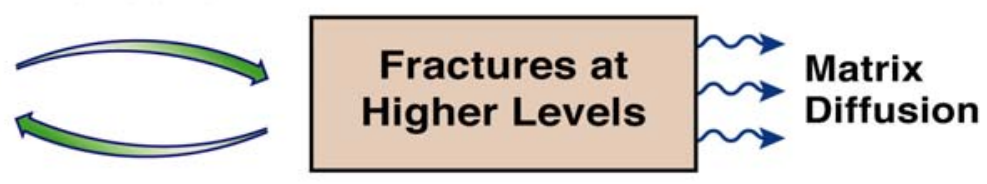


1

2 Figure 9. Fitted relative effective-matrix-diffusion coefficient values (Equation (12)) as a 3 function of distance for the flow path shown in Figure 3.

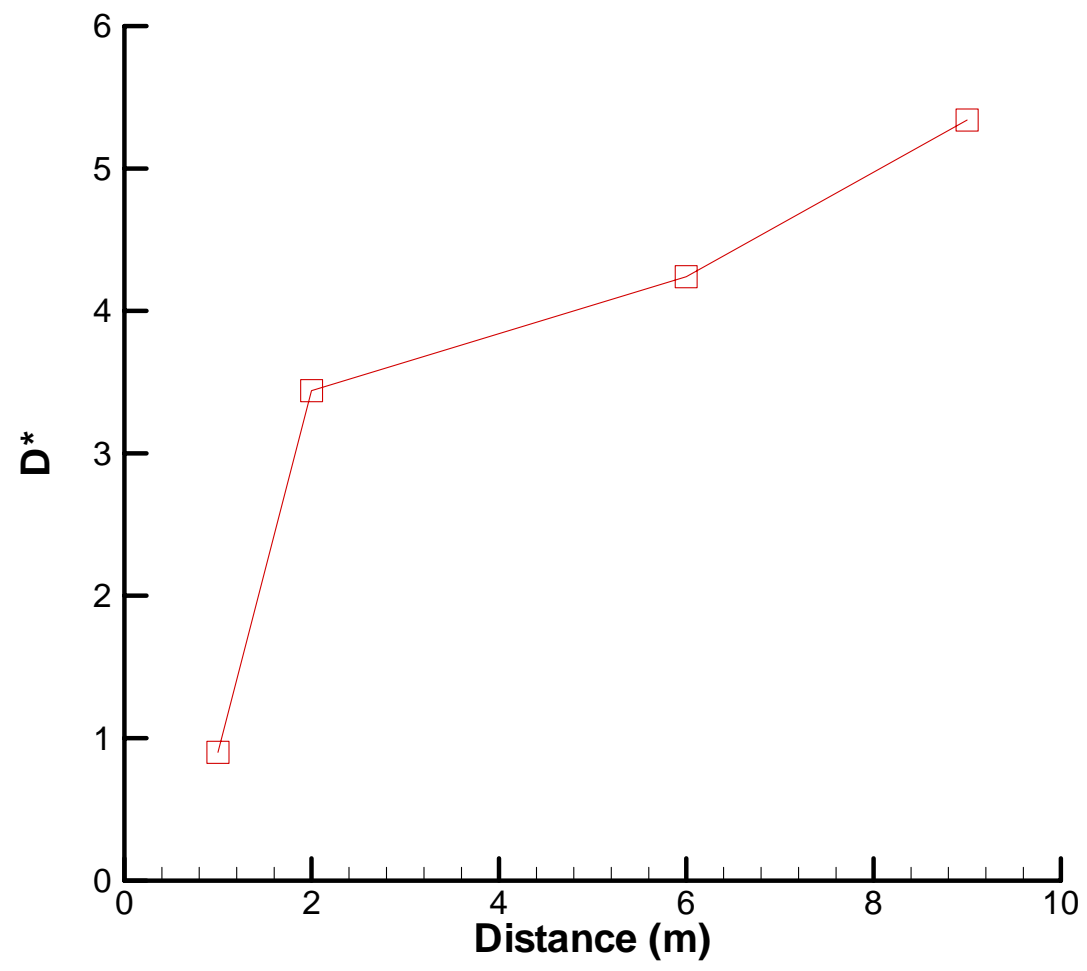


3 Figure 10 A comparison between the simulation results with a portion of data from Zhou 4 et al. (2005b).

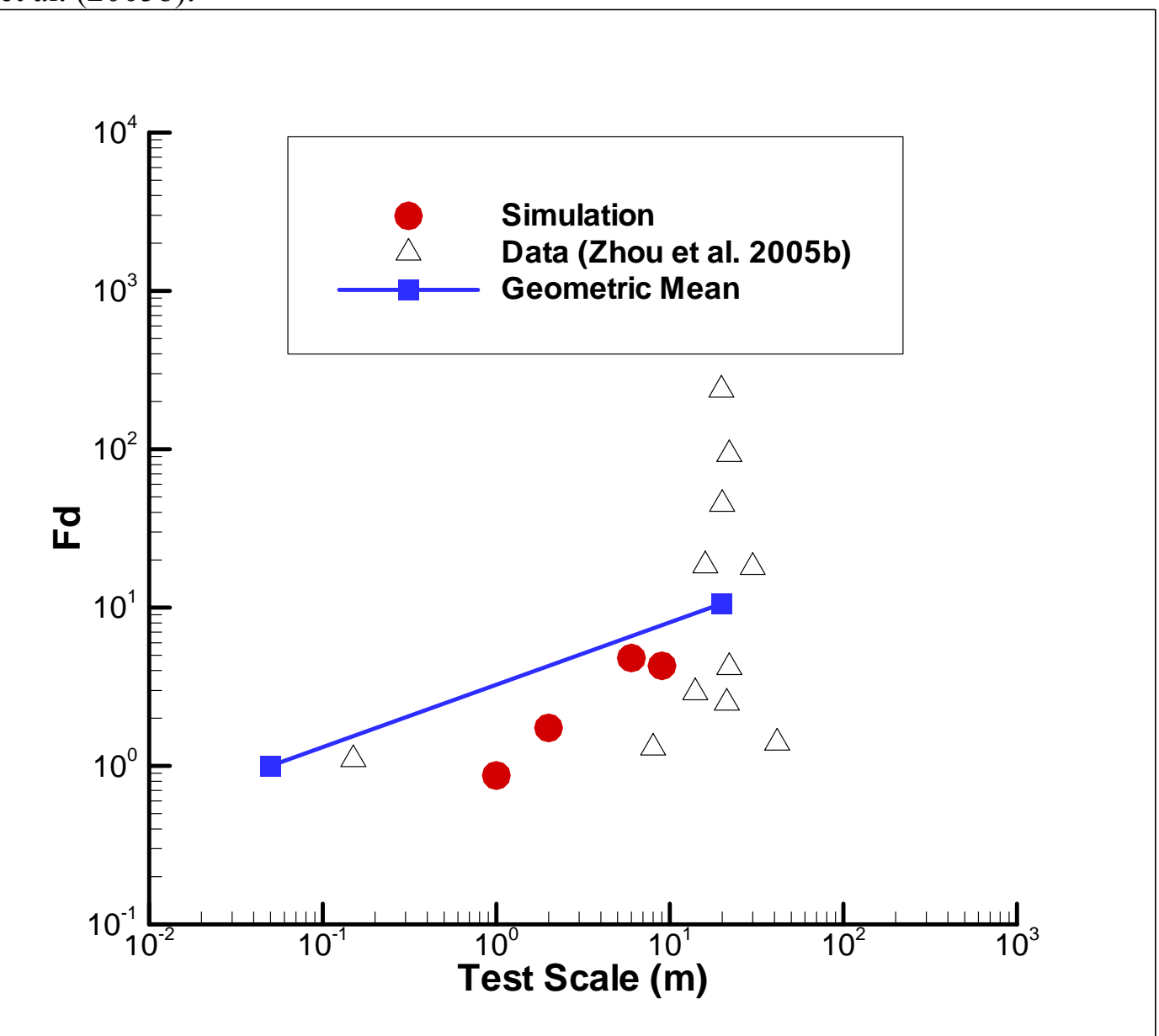

5 
1

2 Table 1. Fitted parameter values for the first flow path (Figure 2)

3

\begin{tabular}{|l|l|l|l|l|}
\hline \multicolumn{1}{|c|}{$\alpha$} & Location & \multicolumn{1}{|c|}{$\mathrm{D}^{*}$} & \multicolumn{1}{|c|}{$\tau$ (day) } & \multicolumn{1}{c|}{$\alpha_{\mathrm{L}}(\mathrm{m})$} \\
\hline 5 & $\mathrm{~B}$ & 0.89 & 1.03 & 0.02 \\
\cline { 2 - 5 } & $\mathrm{C}$ & 1.73 & 2.00 & 0.05 \\
\cline { 2 - 5 } & $\mathrm{D}$ & 5.34 & 10.89 & 2.22 \\
\cline { 2 - 5 } & $\mathrm{E}$ & 5.10 & 14.00 & 3.00 \\
\hline 10 & $\mathrm{~B}$ & 0.76 & 1.03 & 0.02 \\
\cline { 2 - 5 } & $\mathrm{C}$ & 0.95 & 2.07 & 0.05 \\
\cline { 2 - 5 } & $\mathrm{D}$ & 4.91 & 9.00 & 3.00 \\
\cline { 2 - 5 } & $\mathrm{E}$ & 3.96 & 11.89 & 3.00 \\
\hline 20 & $\mathrm{~B}$ & 0.76 & 1.03 & 0.02 \\
\cline { 2 - 5 } & $\mathrm{C}$ & 0.82 & 2.08 & 0.05 \\
\cline { 2 - 5 } & $\mathrm{D}$ & 4.62 & 6.93 & 2.70 \\
\cline { 2 - 5 } & $\mathrm{E}$ & 3.34 & 10.00 & 2.57 \\
\hline
\end{tabular}

4

5

6

7

8

9

10

11

12

13

14

15

16

17

18

19

20

21

22

23

24

25

26

27

28 
1 Table 2. Fitted parameter values for the first flow path with the reduced local-scale 2 diffusion coefficient value (Figure 2)

3

\begin{tabular}{|l|l|l|l|l|}
\hline \multicolumn{1}{|c|}{$\alpha$} & Location & \multicolumn{1}{|c|}{$\mathrm{D}^{*}$} & \multicolumn{1}{|c|}{$\tau$ (day) } & \multicolumn{1}{c|}{$\alpha_{\mathrm{L}}(\mathrm{m})$} \\
\hline \multirow{3}{*}{20} & $\mathrm{~B}$ & 0.0004 & 1.01 & 0.0008 \\
\cline { 2 - 5 } & $\mathrm{C}$ & 0.01 & 2.03 & 0.0016 \\
\cline { 2 - 5 } & $\mathrm{D}$ & 0.17 & 9.26 & 0.28 \\
\cline { 2 - 5 } & $\mathrm{E}$ & 0.18 & 12.00 & 0.21 \\
\hline
\end{tabular}

4

5

6

7

8

9

10

11

12

13

14

15

16

17

18

19

20

21

22

23

24

25

26

27

28

29

30

31

32

33

34

35

36

37

38 
1

2 Table 3. Fitted parameter values for the second flow path (Figure 3)

3

\begin{tabular}{|l|c|l|l|l|}
\hline \multicolumn{1}{|c|}{$\alpha$} & Location & \multicolumn{1}{|c|}{$\mathrm{D}^{*}$} & \multicolumn{1}{c|}{$\tau$ (day) } & \multicolumn{1}{c|}{$\alpha_{\mathrm{L}}(\mathrm{m})$} \\
\hline 5 & $\mathrm{~B}$ & 0.90 & 1.03 & 0.02 \\
\cline { 2 - 5 } & $\mathrm{C}$ & 3.44 & 1.98 & 0.12 \\
\cline { 2 - 5 } & $\mathrm{D}$ & 4.24 & 4.68 & 0.24 \\
\cline { 2 - 5 } & $\mathrm{E}$ & 5.34 & 6.81 & 0.41 \\
\hline
\end{tabular}

4

5

6

7 